\title{
Hospitalization in older patients due to adverse drug reactions - the need for a prediction tool
}

\author{
This article was published in the following Dove Press journal: \\ Clinical Interventions in Aging \\ 2 May 2016 \\ Number of times this article has been viewed
}

\section{Nibu Parameswaran Nair \\ Leanne Chalmers \\ Gregory M Peterson \\ Bonnie J Bereznicki \\ Ronald L Castelino \\ Luke R Bereznicki}

Division of Pharmacy, School of Medicine, Faculty of Health, University of Tasmania, Hobart, TAS, Australia
Correspondence: Nibu Parameswaran Nair Division of Pharmacy, School of Medicine, Faculty of Health, University of Tasmania, Private Bag 26, Hobart, Tasmania, 7001 , Australia

Tel +6I 362261069

Fax +6I 362262870

Email nibu.parameswarannair@utas.edu.au
Abstract: Adverse drug reactions (ADRs) represent a major burden on society, resulting in significant morbidity, mortality, and health care costs. Older patients living in the community are particularly susceptible to ADRs, and are at an increased risk of ADR-related hospitalization. This review summarizes the available evidence on ADR-related hospital admission in older patients living in the community, with a particular focus on risk factors for ADRs leading to hospital admission and the need for a prediction tool for risk of ADR-related hospitalization in these individuals. The reported proportion of hospital admissions due to ADRs has ranged from $6 \%$ to $12 \%$ of all admissions in older patients. The main risk factors or predictors for ADRrelated admissions were advanced age, polypharmacy, comorbidity, and potentially inappropriate medications. There is a clear need to design intervention strategies to prevent ADR-related hospitalization in older patients. To ensure the cost-effectiveness of such strategies, it would be necessary to target them to those older individuals who are at highest risk of ADR-related hospitalization. Currently, there are no validated tools to assess the risk of ADRs in primary care. There is a clear need to investigate the utility of tools to identify high-risk patients to target appropriate interventions toward prevention of ADR-related hospital admissions.

Keywords: adverse drug reactions, hospital admission, prediction, older patients, primary care, risk factors

\section{Introduction}

Medication-related adverse events (AEs) in general practice represent an important cause of morbidity and are thought to cause between $10 \%$ and $30 \%$ of all hospital admissions in older patients. ${ }^{1,2}$ These AEs are defined as "any untoward medical occurrences that may present during treatment with a pharmaceutical product but which does not necessarily have a causal relationship with this treatment". ${ }^{3}$ Among these AEs, adverse drug reactions (ADRs) represent a major burden, causing significant morbidity, mortality, and health care costs. ${ }^{4,5}$ The World Health Organization defines an ADR as any noxious, unintended, and undesired effect of a drug, excluding therapeutic failures, intentional and accidental poisoning, and drug abuse. ${ }^{6,7}$ ADRs can be assessed as severe, moderate, or mild reactions. ${ }^{8}$ A severe ADR is life-threatening, causing permanent damage or requiring intensive care. Moderate ADRs require hospital admission, a change in therapy, or specific treatment. In a meta-analysis of prospective studies, 1,00,000 deaths per year could be attributed to ADRs in the USA, which highlights the seriousness and extent of the problem. ${ }^{9}$ Furthermore, a Swedish study estimated that $3.1 \%$ of deaths in the general population (including subjects who died in and outside hospitals) were attributed to ADRs. ${ }^{10}$

Older patients are particularly susceptible to ADRs due to multiple comorbidities, cognitive and functional impairment, a high prevalence of multiple 
medications (polypharmacy), ${ }^{11}$ and age-related changes in pharmacokinetics and pharmacodynamics. ${ }^{5}$ A significant consequence of ADRs in older adults living in the community is hospitalization and its related costs. ${ }^{12}$ These patients then become susceptible to hospitalization-related complications, such as cardiovascular and neurological disorders, nosocomial infections, and deconditioning. ${ }^{13}$ It may be challenging for primary care physicians (or general practitioners [GPs]) to easily identify patients who are at risk of hospitalization due to ADRs, partly due to significant time pressures in office-based practice. ${ }^{14}$ This narrative review explores our current understanding of ADR-related hospitalization in older patients, with a particular focus on risk factors and the need for a prediction tool for ADR-related hospitalization for utilization in community settings.

\section{ADR-related hospitalization in older patients - how significant is the problem?}

Based on a retrospective cohort study in a veteran population (median age 81 years), the overall proportion of potentially preventable medication-related hospitalizations was $20.3 \%$ over a 5-year period. ${ }^{8}$ ADRs were the most common cause, accounting for one-third of hospitalizations based on a study by Chan et al. ${ }^{15}$ Data collected from GP encounters in 2003-2004 in Australia indicated that ADRs represented the most common adverse drug event (ADE) in the community (72\%), of which the majority were moderate or severe and required hospitalization. ${ }^{16}$ The proportion of all hospital admissions due to ADRs has ranged from $6 \%$ to $12 \%$ among older patients. ${ }^{12,17-20}$ Also, one study conducted in Canada found that emergency department visits and hospital admissions due to ADRs in older patients cost an estimated US\$35.7 million annually. ${ }^{21}$

\section{Severity, causality, and avoidability of ADR-related hospitalization in older patients}

ADR-related hospitalization can lead to fatal outcomes and increased length of stay in older patients. ${ }^{22,23}$ The severity of ADR-related admissions was assessed in a prospective study, in which $18.6 \%$ of cases were identified as severe ADRs. ${ }^{24}$ The most severe ADRs were related to hemorrhage and other hematological disorders, and acute renal failure. Most of the ADRs causing hospital admission in older patients were type A reactions, which are predictable from the known pharmacology of the drug, ${ }^{22,23}$ whereas type B reactions (bizarre or non-dose-related reactions) accounted for only $8.1 \%$ based on a cross-sectional study. ${ }^{23}$

Since ADRs are a major cause of morbidity and mortality, it is important to demonstrate a causal relationship between the drug and the adverse clinical event. Furthermore, it is often difficult to decide if an adverse clinical event is an ADR or due to deterioration in the patient's disease state. Therefore, causality assessment is used to determine the likelihood that a drug caused a suspected ADR. ${ }^{25}$ The most widely used and generally accepted causality assessment scales in clinical practice are the probability scales developed by the World Health Organization Collaborating Centre for International Drug Monitoring (Uppsala Monitoring Centre, Sweden) and the Naranjo ADR Probability Scale. ${ }^{26,27}$ These scales use inter-rater agreement scores, which are superior to subjective clinical judgment. However, they can be difficult to interpret in the context of older patients with multiple comorbidities and medications. ${ }^{28}$ Based on different studies, the majority of ADRs in older adults leading to hospital admission were either probable or possible based on causality assessments. ${ }^{22,24,29}$ Definite or certain ADRs accounted for only $4 \%$ and $6.8 \%$, respectively, in some studies. ${ }^{18,29}$

While some ADR-related hospitalizations are unavoidable, even with the most extraordinary precautions (eg, immunological reactions), more than half of hospital admissions for ADRs are preventable. ${ }^{8}$ Potentially avoidable ADRs leading to hospital admission in older adults could be due to improper dosage, missed contraindications and drug interactions, or reexposure of patients who had known drug allergies. ADRs can be classified into definitely avoidable, possibly avoidable, unavoidable, and unclassifiable based on the Halls criteria. ${ }^{30}$ Among the ADRs causing hospital admission in older patients, most were either definitely or possibly avoidable, with only $18.6 \%-28 \%$ of cases considered unavoidable. ${ }^{18,22}$

\section{Most common ADRs causing hospitalization in older patients}

Advancing age can contribute to a significant increase in sensitivity to particular drugs and a corresponding increase in the incidence of ADRs. ${ }^{31}$ Older patients demonstrate an exaggerated response to central nervous system-active drugs (eg, benzodiazepines, anesthetics, opioids) and a decreased response to some cardiovascular agents (eg, beta-adrenergic agents). ${ }^{32}$ Also, the most important pharmacokinetic changes in older people include a decrease in the excretory capacity of the kidney, rather than a decline in the rate of hepatic drug metabolism. ${ }^{33}$ The most frequent ADRs causing hospital 
Table I Most common ADRs causing hospitalization in the elderly

\begin{tabular}{ll}
\hline Most common ADRs & Examples \\
\hline $\begin{array}{l}\text { Gastrointestinal } \\
\text { complications }^{5,18,22-24}\end{array}$ & $\begin{array}{l}\text { Gastrointestinal bleeding, peptic ulcer, } \\
\text { erosive gastritis, nausea, vomiting } \\
\text { Cardiovascular }\end{array}$ \\
$\begin{array}{l}\text { disorders } \\
\text { Met, } 18,19,22\end{array}$ & $\begin{array}{l}\text { arrhythmias } \\
\text { Hypoglycemia }\end{array}$ \\
complications $^{5,12,24}$ & Renal impairment, acute renal failure \\
Renal and urinary & \\
disorders & \\
Electrolyte disorders $^{20,22}$ & Hypokalemia, hyperkalemia, \\
Nervous system & hyponatremia \\
disorders & Depressed level of consciousness, \\
\hline
\end{tabular}

Abbreviation: ADRs, adverse drug reactions.

admission in older patients are typically gastrointestinal disorders ${ }^{5,18,22-24}$ and cardiovascular and metabolic/endocrine complications. ${ }^{5,12,18,19,22,24}$ A summary of the most common ADRs causing hospitalization in older patients is shown in Table 1.

\section{Drugs most frequently causing ADR-related hospitalization in older patients}

Older patients, due to the presence of multiple disease states, frequently use medications including prescription, overthe-counter, and herbal preparations. According to a survey conducted in 3,005 community-dwelling older adults aged 57-85 years in the USA, at least one prescription medication was used by $81 \%$ of the overall survey population and five or more prescription medications were used by $36 \%$ of people aged 75-85 years. ${ }^{34}$ The drugs most frequently causing ADR-related hospital admissions in older patients have varied between studies; these findings are summarized in Table 2.

Table 2 Most common drugs causing ADR-related hospital admission in the elderly

Antibacterials ${ }^{5,18,20}$

Anticonvulsants ${ }^{58}$

Antineoplastic agents ${ }^{5,35}$

Antipsychotics ${ }^{5,35}$

Antithrombotics (anticoagulants and antiplatelets) $18,20,23,24,35,58$

Cardiovascular drugs (diuretics, $5,20,22-24,35$ cardiac glycosides, ${ }^{5,18,58}$

angiotensin-converting enzyme inhibitors, ${ }^{18,23,24,29,58}$ beta-blockers, ${ }^{29,58}$

antiarrhythmics, 18,24 calcium channel blockers ${ }^{5}$ )

Corticosteroids ${ }^{5}$

Hypoglycemics ${ }^{35,58}$

Nonsteroidal anti-inflammatory drugs s, $18,22-24,58$

Abbreviation: ADR, adverse drug reaction.

\section{Predictors of and risk factors for ADR-related hospitalization in older patients}

Despite concerns that ADRs represent an important medical problem in older patients, the predictive factors are still poorly understood, particularly in the community-dwelling elderly. The characteristics and major findings of studies that have investigated the risk factors for ADR-related hospital admission in older patients are shown in Table 3.

Age as a significant contributing factor to ADR-related hospitalization had been observed in community-dwelling older patients in some studies. ${ }^{5,21,23}$ The odds of experiencing severe ADRs increased by 3\% per 1-year increase in age above 66 years. ${ }^{21}$

The number of drugs being taken has also been highlighted in many studies as an independent risk factor for ADR-related hospital admissions. . $^{5,12,17,21,23,24,35-38}$ It has been estimated that the chance of an older patient having an ADR increases from $10 \%$, when one medication is used, to $75 \%$ if more than five medications are used concurrently. ${ }^{39}$ The risk increase of an older patient (mean age 70 years) having an ADR-related hospitalization is $24 \%$ for each drug increase. ${ }^{5}$

The prevalence of multimorbidity (the coexistence of multiple chronic diseases) in older patients ranges from $55 \%$ to $98 \%$ based on the systematic reviews. ${ }^{40}$ The presence of comorbidity also predicted ADR-related hospitalization in community-dwelling older patients..$^{5,19,21,36,41}$ Relevant comorbidities included ischemic heart disease; heart failure; depression; diabetes; peripheral vascular disease; and pulmonary, rheumatological, hepatic, renal, and malignant diseases. In a population-based retrospective study, comorbidity predicted repeat admission for ADRs in older patients, especially those with comorbidities often managed in the community. ${ }^{41}$

Potentially inappropriate drug prescribing is highly prevalent among community-dwelling older patients, and potentially inappropriate medications (PIMs) in these patients are significantly associated with ADRs and subsequent hospital admission. ${ }^{42,43}$ According to Price et al, exposure to a PIM from the Beers list of medications was associated with a significant increase in unplanned hospitalizations (odds ratio [OR] 1.18, 95\% confidence interval [CI] 1.15-1.21). ${ }^{44}$ There was also an increase in inpatient visits (OR 1.99, 95\% CI 1.76-2.26) in older patients who were prescribed PIMs based on a retrospective cohort study. ${ }^{45}$

A range of other factors has also been associated with ADR-related hospitalization, but these associations have 


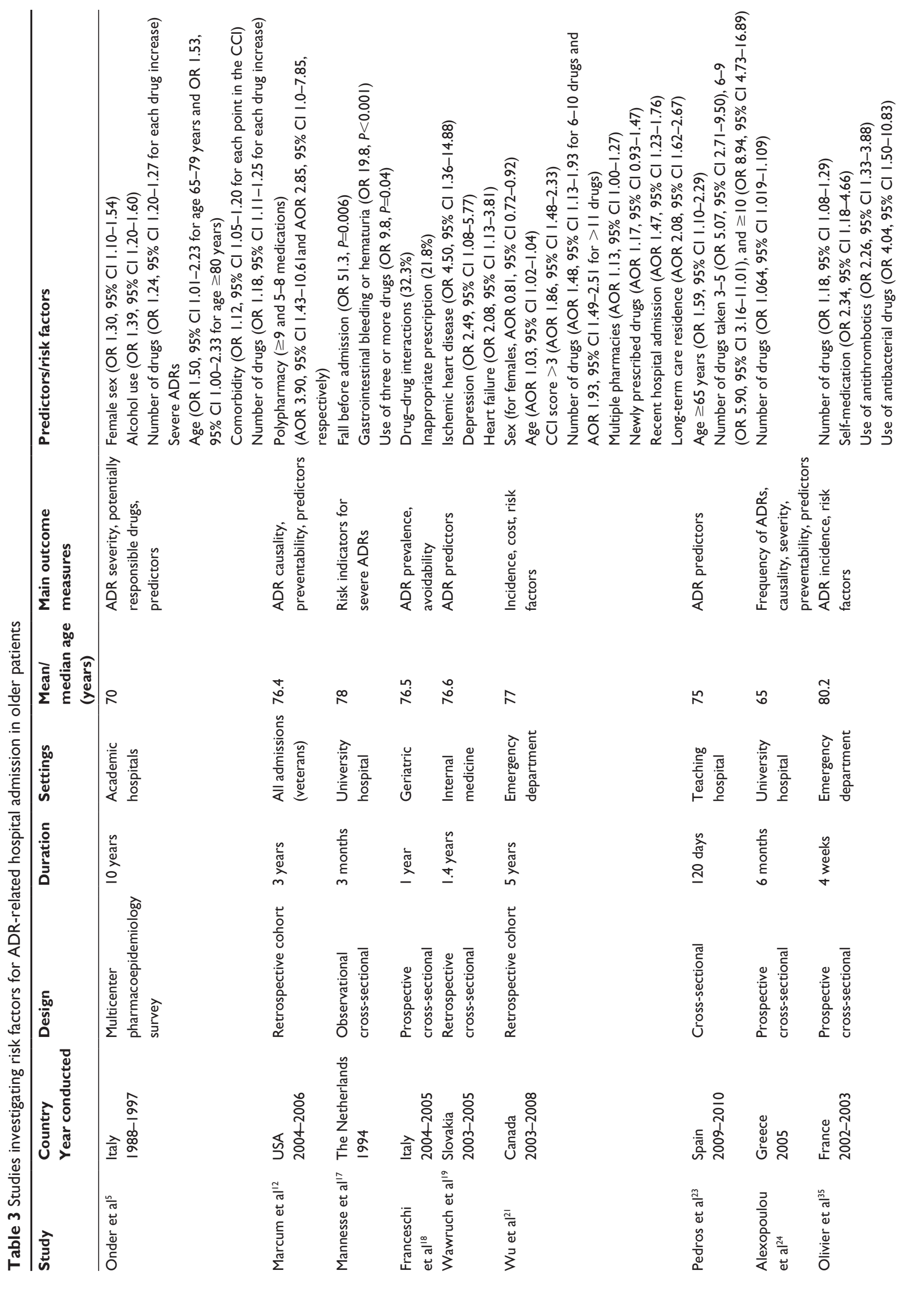




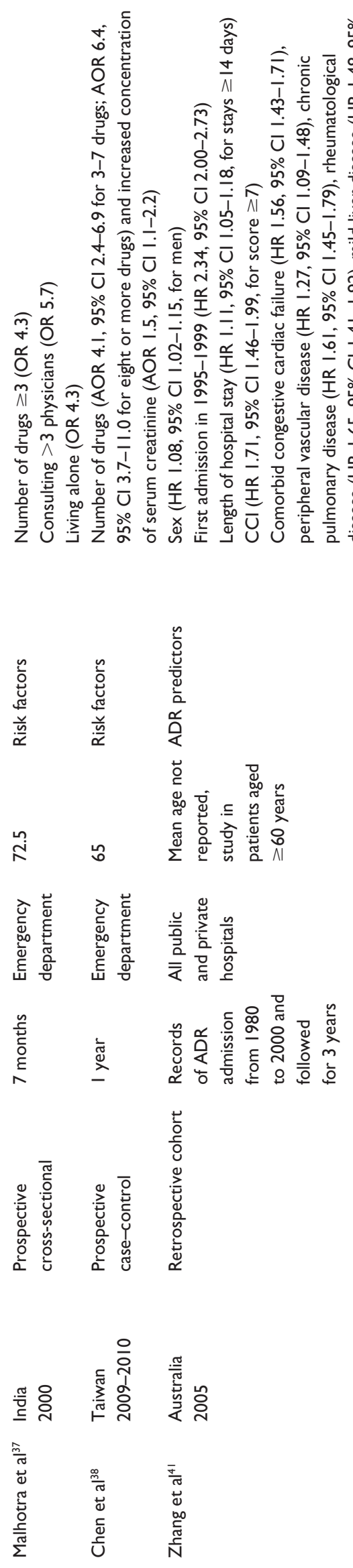

been less consistently described. The presence of drug interactions was identified as a risk factor for ADRs in one study. ${ }^{18}$ Female sex was also associated with ADR-related hospitalization in older patients based on a study by Onder et al. ${ }^{5}$ However, sex was not found to be an independent risk factor based on a cross-sectional study ${ }^{23}$ An overview of the predictors of ADR-related hospitalization in older patients is provided in Table 4 .

\section{The need for an ADR prediction tool in older patients in primary care}

Prediction tools use multiple predictors to estimate the absolute risk that a certain outcome is present and enable the stratification of individuals or group of individuals by these risks. ${ }^{46}$ They are usually developed to guide health care professionals in their decision making regarding further management and to inform individuals about their risk of experiencing a certain outcome.$^{47}$ Risk prediction models for ADRs have begun to emerge in recent years, which aim to assist health care professionals to make clinical and therapeutic decisions to minimize the risk of drug-related harm, especially in the older population having the highest risk of ADRs. ${ }^{7,48,49}$ This will help the physician and the pharmacist to pay extra attention to a patient's medications when they are identified as being at risk. ${ }^{49}$

It is often difficult to predict the occurrence of ADRs in older patients for several reasons. The presentation of an ADR is often atypical and nonspecific in nature, which can be misinterpreted as a new medical problem or a complication relating to a preexisting diagnosis. ${ }^{50}$ This may lead to the addition of another drug to treat the symptoms (referred to as a "prescribing cascade" ${ }^{51}$ ), which will again increase the risk of drug-drug interactions and another ADR. ${ }^{52}$ Sometimes, due to inappropriate polypharmacy, there is a chance that two or more drugs taken by the patient may lead to the same ADR..$^{53}$ The prediction of ADRs is especially challenging in patients with dementia and cognitive impairment since problems with the patient's communication and reporting of adverse effects might reduce the clinician's ability to detect ADRs. ${ }^{54}$ Hence, identification of the various risk factors for ADRs and predicting highrisk elderly patients is essential for better therapy outcomes and targeting additional resources toward this group. ${ }^{49}$ To our knowledge, there are no empirical data that allow stratification of community-dwelling older people according to the likelihood of ADRs leading to hospital admission. A fundamental problem is that there is only a limited understanding of the risk factors associated with ADR-related hospitalization in the older population living in the community. Also, considerably 
Table 4 An overview of predictors of ADR-related hospital admission in the elderly

\begin{tabular}{|c|c|}
\hline Frequently reported predictors & Other predictors \\
\hline Number of medications $s^{5,12,17,21,23,24,35-38}$ & Drug interactions $^{18}$ \\
\hline Comorbid conditions $s^{5,19,21,36,41}$ & Female sex ${ }^{5}$ \\
\hline $\mathrm{Age}^{5,21,23}$ & Self-medication ${ }^{35}$ \\
\hline Potentially inappropriate & Use of antithrombotics ${ }^{35}$ \\
\hline \multirow[t]{18}{*}{ medications $^{44,45}$} & Use of antibacterial drugs $\mathrm{s}^{35}$ \\
\hline & Alcohol use $\mathrm{e}^{5}$ \\
\hline & Falls before admission ${ }^{17}$ \\
\hline & Patients living alone ${ }^{37}$ \\
\hline & Increased serum creatinine ${ }^{38}$ \\
\hline & Multiple pharmacy visits ${ }^{21}$ \\
\hline & More than three consulting \\
\hline & physicians $^{37}$ \\
\hline & Newly prescribed drugs ${ }^{21}$ \\
\hline & Recent hospital admission ${ }^{21}$ \\
\hline & Long-term care residence ${ }^{21}$ \\
\hline & Patients with diabetes or \\
\hline & neoplasms $^{37}$ \\
\hline & Gastrointestinal bleeding or \\
\hline & hematuria $^{17}$ \\
\hline & Ischemic heart disease ${ }^{19}$ \\
\hline & Depression $^{19}$ \\
\hline & Heart failure ${ }^{19}$ \\
\hline
\end{tabular}

Abbreviation: ADR, adverse drug reaction.

more research has been focused on ADRs occurring in the hospital than in the community setting. ${ }^{55}$

The contemporary validated ADR risk prediction tools used in hospital settings, detailed in Table 5, could be used as guides to develop similar models in community settings.
The GerontoNet ADR risk score is one such validated model proposed by Onder et al to identify hospitalized patients who are at an increased risk of an ADR. ${ }^{49}$ This risk score identified several risk factors for the development of ADRs and developed a score that allows stratification of patients according to the likelihood of an ADR. The strongest predictors of ADRs in this study were the number of medications and a history of an ADR, followed by the presence of heart failure, liver disease, four or more medical conditions, and renal failure. The GerontoNet ADR risk score was reported to have satisfactory predictive value for ADRs with an area under the curve (AUC) of 0.71 (95\% CI 0.68-0.73)..$^{7,49}$ But, one of the important limitations of this study was that data on the preventability of ADRs were not collected, so the authors could not assess the risk factors for preventable ADRs. Also, these study findings cannot be extrapolated to older patients living in the community setting since the data were collected based on hospitalized patients 65 years or above. Another important limitation is that the GerontoNet ADR risk score did not account for the use of PIMs as a risk factor, which could be a stronger predictor of ADRs.

O'Connor et al investigated the clinical applicability and the ability to predict ADRs using the GerontoNet ADR risk score in hospitalized older patients. ${ }^{7}$ The variables that increased ADR risk in their alternative model included renal failure, increasing number of medications, inappropriate medications, and age $\geq 75$ years. The study results showed

Table 5 Features of validated ADR prediction tools for elderly hospitalized patients

\begin{tabular}{|c|c|c|}
\hline Features & $\begin{array}{l}\text { Onder et } \mathrm{al}^{49} \\
\text { (GerontoNet ADR risk score) }\end{array}$ & $\begin{array}{l}\text { Tangiisuran et al }{ }^{48} \\
\text { (BADRI) model }\end{array}$ \\
\hline \multicolumn{3}{|l|}{ Study design } \\
\hline Developmental stage & Retrospective cohort & Prospective cohort \\
\hline Validation stage & Prospective cohort & Prospective cohort \\
\hline Main outcome measure & $\operatorname{ADR}(6.5 \%)$ & $\operatorname{ADR}(12.5 \%)$ \\
\hline \multirow[t]{2}{*}{ Age of study participants (years) } & Mean (SD) & Median (IQR) \\
\hline & $78(7.2)$ & $85(81-89)$ \\
\hline Most common ADRs & Cardiovascular and arrhythmic complications & - \\
\hline \multirow[t]{6}{*}{ Predictors of ADRs } & $\geq 4$ Comorbid conditions & $\geq 8$ drugs \\
\hline & Heart failure & Hyperlipidemia \\
\hline & Liver disease & Raised white cell count \\
\hline & Number of drugs & Use of antidiabetic agents \\
\hline & History of ADR & Length of stay $\geq 12$ days \\
\hline & Renal failure & \\
\hline \multicolumn{3}{|c|}{ Predictive ability of risk score (AUROC) } \\
\hline Developmental stage & $0.7 \mathrm{I}(95 \% \mathrm{Cl} 0.68-0.73)$ & $0.74(95 \% \mathrm{Cl} 0.68-0.79)$ \\
\hline Validation stage & $0.70(95 \% \mathrm{Cl} 0.63-0.78)$ & $0.73(95 \% \mathrm{Cl} 0.66-0.80)$ \\
\hline Cutoff score & Between 3 and 4 & $>1$ \\
\hline Sensitivity & $68 \%$ & $80 \%$ \\
\hline Specificity & $65 \%$ & $55 \%$ \\
\hline
\end{tabular}

Abbreviations: $A D R$, adverse drug reaction; $A U R O C$, area under the receiver operating characteristic curve; $\mathrm{Cl}$, confidence interval; SD, standard deviation; IQR, interquartile range. 
that $37.7 \%$ of ADRs were not predicted by the GerontoNet ADR risk score. The authors' model included additional predictors like PIMs which would influence the presence of ADRs, but had a lower predictive value for ADRs (AUC of 0.62 [95\% CI $0.57-0.68]$ ) compared to the GerontoNet ADR risk score.

Tangiisuran et al recently developed and validated an ADR risk model in a population of patients with a median age of 85 years. ${ }^{48}$ This model was based on five clinical variables, some of which have not been previously reported. Compared with the GerontoNet ADR risk score and the model developed by O'Connor et al, this model had a higher predictive value for ADRs. Again, this model did not account for the use of PIMs as a risk factor. Also, this model did not use a uniform criterion for causality assessment of ADRs, which might have affected the outcome of the study.

The utility of an ADE trigger tool had been explored in a few studies conducted among older patients living in the community. One such tool used a 39-item trigger tool in patients aged 65 years or above in ambulatory primary care practices. ${ }^{56}$ The most common triggers and their positive predictive values (PPVs) for ADE were "Medication stop" (26.3\%), "Hospitalization" (21.8\%), and "Emergency Room visit" (14.9\%). Most of the triggers had very low PPVs and only nine of the triggers had PPVs $>5 \%$ which could detect $94.4 \%$ of the ADEs. Similarly, the utility of an ADE trigger tool in Veterans Affairs nursing homes has also been studied and found an overall PPV of $40.1 \% .^{57}$ The most common ADEs detected by this tool were acute kidney injury, hypokalemia, hypoglycemia, and hyperkalemia. Even though these tools could be used to identify ADEs in community-dwelling older patients, there is a clear need to predict the future occurrence of these events, especially ADRs.

\section{Development of an ADR prediction tool for older patients in primary care}

A study has suggested that the majority of older patients had their own family physicians (95\%) at the time of presenting to the emergency department due to ADRs. ${ }^{21}$ Primary care physicians are best able to understand the complete medical, functional, and social issues that are in play when optimizing medications in older people living in the community. Since the older population is likely to have multiple risk factors for ADRs, ideally, the GPs should be able to predict those older adults who have a severe risk of ADRs that may lead to emergency hospital admissions. The development of an ADR prediction tool in community settings would facilitate this. The design of such a tool would require identification of a comprehensive list of possible predictive factors contributing to ADR-related hospitalization based on the literature, available validated ADR prediction tools, and clinical experience. These predictive factors could then be quantified in large populations of elderly subjects admitted and not admitted to hospital with an ADR preferably using a prospective study design. Univariate and multivariate analyses could be undertaken and the significant predictors of ADR-related hospitalization assigned a score based on their respective ORs. Finally, an ADR risk score could be computed based on the sum of the scores of individual variables as described by Onder et al, with a subsequent validation stage. ${ }^{49} \mathrm{~A}$ risk score may also be used to improve prescribing practice. The ADR risk score could potentially be integrated into prescribing software to alert GPs regarding their patients' risk of ADRs and prompt appropriate preventive measures, which might include medication review in high-risk patients, avoiding inappropriate medications, comprehensive geriatric assessment, ${ }^{4}$ and cessation of high-risk medications which are least likely to be beneficial. Similarly, policy makers could use the score to target limited health care resources to patients in real need of intervention to address the issue of quality use of medicines.

\section{Conclusion}

It is clear that older patients are at significant risk of hospital admissions due to ADRs and many ADRs occurring in this population are considered preventable. There is a need for greater understanding of the predictors of ADRs in these patients, and how these predictors are interrelated. This will provide the basis for improved risk assessment practices. Even though various risk models in older populations have been suggested for use in hospital settings, there is a clear need for a simple, practical, and efficient tool to identify the high-risk group of older patients most likely to be admitted to hospital due to ADRs. These patients can be targeted in order to reduce their risk of ADRs and their associated morbidity and costs.

\section{Disclosure}

The authors report no conflicts of interest in this work.

\section{References}

1. Royal S, Smeaton L, Avery AJ, Hurwitz B, Sheikh A. Interventions in primary care to reduce medication related adverse events and hospital admissions: systematic review and meta-analysis. Qual Saf Health Care. 2006;15(1):23-31. 
2. Thomas R, Huntley AL, Mann M, et al. Pharmacist-led interventions to reduce unplanned admissions for older people: a systematic review and meta-analysis of randomised controlled trials. Age Ageing. 2014; 43(2):174-187.

3. Nebeker JR, Barach P, Samore MH. Clarifying adverse drug events: a clinician's guide to terminology, documentation, and reporting. Ann Intern Med. 2004;140(10):795-801.

4. Onder G, van der Cammen TJ, Petrovic M, Somers A, Rajkumar C. Strategies to reduce the risk of iatrogenic illness in complex older adults. Age Ageing. 2013;42(3):284-291.

5. Onder G, Pedone C, Landi F, et al. Adverse drug reactions as cause of hospital admissions: results from the Italian Group of Pharmacoepidemiology in the Elderly (GIFA). J Am Geriatr Soc. 2002;50(12): 1962-1968.

6. World Health Organization. International Drug Monitoring: The Role of the Hospital. Geneva, Switzerland: World Health Organization; 1966. Technical Report Series No. 425. Available from: http:/www.who.int/ mediacentre/factsheets/fs293/en/. Accessed December 1, 2015.

7. O'Connor MN, Gallagher P, Byrne S, O'Mahony D. Adverse drug reactions in older patients during hospitalisation: are they predictable? Age Ageing. 2012;41(6):771-776.

8. Chan M, Nicklason F, Vial JH. Adverse drug events as a cause of hospital admission in the elderly. Intern Med J. 2001;31(4):199-205.

9. Lazarou J, Pomeranz BH, Corey PN. Incidence of adverse drug reactions in hospitalized patients: a meta-analysis of prospective studies. JAMA. 1998;279(15):1200-1205.

10. Wester K, Jonsson AK, Spigset O, Druid H, Hagg S. Incidence of fatal adverse drug reactions: a population based study. Br J Clin Pharmacol. 2008;65(4):573-579.

11. Onder G, Liperoti R, Fialova D, et al. Polypharmacy in nursing home in Europe: results from the SHELTER study. $J$ Gerontol A Biol Sci Med Sci. 2012;67(6):698-704.

12. Marcum ZA, Amuan ME, Hanlon JT, et al. Prevalence of unplanned hospitalizations caused by adverse drug reactions in older veterans. J Am Geriatr Soc. 2012;60(1):34-41.

13. Lim SC, Doshi V, Castasus B, Lim JK, Mamun K. Factors causing delay in discharge of elderly patients in an acute care hospital. Ann Acad Med Singapore. 2006;35(1):27-32.

14. Cutler DM, Everett W. Thinking outside the pillbox - medication adherence as a priority for health care reform. $N$ Engl J Med. 2010;362(17): 1553-1555.

15. Kalisch LM, Caughey GE, Barratt JD, et al. Prevalence of preventable medication-related hospitalizations in Australia: an opportunity to reduce harm. Int J Qual Health Care. 2012;24(3):239-249.

16. Miller GC, Britth HC, Valenti L. Adverse drug events in general practice patients in Australia. Med J Aust. 2006;184(7):321-324.

17. Mannesse CK, Derkx FH, de Ridder MA, Man in 't Veld AJ, van der Cammen TJ. Contribution of adverse drug reactions to hospital admission of older patients. Age Ageing. 2000;29(1):35-39.

18. Franceschi M, Scarcelli C, Niro V, et al. Prevalence, clinical features and avoidability of adverse drug reactions as cause of admission to a geriatric unit: a prospective study of 1756 patients. Drug Saf. 2008;31(6): 545-556.

19. Wawruch M, Zikavska M, Wsolova L, et al. Adverse drug reactions related to hospital admission in Slovak elderly patients. Arch Gerontol Geriatr. 2009;48(2):186-190.

20. Conforti A, Costantini D, Zanetti F, Moretti U, Grezzana M, Leone R. Adverse drug reactions in older patients: an Italian observational prospective hospital study. Drug Healthc Patient Saf. 2012;4:75-80.

21. Wu C, Bell CM, Wodchis WP. Incidence and economic burden of adverse drug reactions among elderly patients in Ontario emergency departments: a retrospective study. Drug Saf. 2012;35(9):769-781.

22. Pirmohamed M, James S, Meakin S, et al. Adverse drug reactions as cause of admission to hospital: prospective analysis of 18820 patients. BMJ. 2004;329(7456):15-19.

23. Pedros C, Quintana B, Rebolledo M, Porta N, Vallano A, Arnau JM. Prevalence, risk factors and main features of adverse drug reactions leading to hospital admission. Eur J Clin Pharmacol. 2014;70(3):361-367.
24. Alexopoulou A, Dourakis SP, Mantzoukis D, et al. Adverse drug reactions as a cause of hospital admissions: a 6-month experience in a single center in Greece. Eur J Intern Med. 2008;19(7):505-510.

25. Parida S. Clinical causality assessment for adverse drug reactions. Indian J Anaesth. 2013;57(3):325-326.

26. Belhekar MN, Taur SR, Munshi RP. A study of agreement between the Naranjo algorithm and WHO-UMC criteria for causality assessment of adverse drug reactions. Indian J Pharmacol. 2014;46(1):117-120.

27. Naranjo CA, Busto U, Sellers EM, et al. A method for estimating the probability of adverse drug reactions. Clin Pharmacol Ther. 1981;30(2): 239-245.

28. Hamilton HJ, Gallagher PF, O’Mahony D. Inappropriate prescribing and adverse drug events in older people. BMC Geriatr. 2009;9:5.

29. Ahern F, Sahm LJ, Lynch D, McCarthy S. Determining the frequency and preventability of adverse drug reaction-related admissions to an Irish University Hospital: a cross-sectional study. Emerg Med J. 2014;31(1):24-29.

30. Hallas J, Harvald B, Gram LF, et al. Drug related hospital admissions: the role of definitions and intensity of data collection, and the possibility of prevention. J Intern Med. 1990;228(2):83-90.

31. Hughes SG. Prescribing for the elderly patient: why do we need to exercise caution? Br J Clin Pharmacol. 1998;46(6):531-533.

32. Bowie MW, Slattum PW. Pharmacodynamics in older adults: a review. Am J Geriatr Pharmacother. 2007;5(3):263-303.

33. ElDesoky ES. Pharmacokinetic-pharmacodynamic crisis in the elderly. Am J Ther. 2007;14(5):488-498.

34. Qato DM, Alexander GC, Conti RM, Johnson M, Schumm P, Lindau ST. Use of prescription and over-the-counter medications and dietary supplements among older adults in the United States. JAMA. 2008;300(24):2867-2878.

35. Olivier P, Bertrand L, Tubery M, Lauque D, Montastruc JL, LapeyreMestre M. Hospitalizations because of adverse drug reactions in elderly patients admitted through the emergency department: a prospective survey. Drugs Aging. 2009;26(6):475-482.

36. Ventura MT, Laddaga R, Cavallera P, et al. Adverse drug reactions as the cause of emergency department admission: focus on the elderly. Immunopharmacol Immunotoxicol. 2010;32(3):426-429.

37. Malhotra S, Karan RS, Pandhi P, Jain S. Drug related medical emergencies in the elderly: role of adverse drug reactions and non-compliance. Postgrad Med J. 2001;77(913):703-707.

38. Chen YC, Fan JS, Chen MH, et al. Risk factors associated with adverse drug events among older adults in emergency department. Eur J Intern Med. 2014;25(1):49-55.

39. Byles JE, Heinze R, Nair BK, Parkinson L. Medication use among older Australian veterans and war widows. Intern Med J. 2003;33(8): 388-392.

40. Marengoni A, Angleman S, Melis R, et al. Aging with multimorbidity: a systematic review of the literature. Ageing Res Rev. 2011;10(4):430-439.

41. Zhang M, Holman CD, Price SD, Sanfilippo FM, Preen DB, Bulsara MK. Comorbidity and repeat admission to hospital for adverse drug reactions in older adults: retrospective cohort study. BMJ. 2009;338:a2752.

42. Ryan C, O’Mahony D, Kennedy J, Weedle P, Byrne S. Potentially inappropriate prescribing in an Irish elderly population in primary care. Br J Clin Pharmacol. 2009;68(6):936-947.

43. Lin YJ, Peng LN, Chen LK, Lin MH, Hwang SJ. Risk factors of potentially inappropriate medications among older patients visiting the community health center in rural Taiwan. Arch Gerontol Geriatr. 2011;53(2): 225-228.

44. Price SD, Holman CD, Sanfilippo FM, Emery JD. Association between potentially inappropriate medications from the Beers criteria and the risk of unplanned hospitalization in elderly patients. Ann Pharmacother. 2014;48(1):6-16.

45. Fick DM, Mion LC, Beers MH, L Waller J. Health outcomes associated with potentially inappropriate medication use in older adults. Res Nurs Health. 2008;31(1):42-51.

46. Moons KG, Kengne AP, Grobbee DE, et al. Risk prediction models: II. External validation, model updating, and impact assessment. Heart. 2012;98(9):691-698 
47. Moons KG, Royston P, Vergouwe Y, Grobbee DE, Altman DG. Prognosis and prognostic research: what, why, and how? BMJ. 2009; 338:b375.

48. Tangiisuran B, Scutt G, Stevenson J, et al. Development and validation of a risk model for predicting adverse drug reactions in older people during hospital stay: Brighton Adverse Drug Reactions Risk (BADRI) model. PLoS One. 2014;9(10):e111254.

49. Onder G, Petrovic M, Tangiisuran B, et al. Development and validation of a score to assess risk of adverse drug reactions among in-hospital patients 65 years or older: the GerontoNet ADR risk score. Arch Intern Med. 2010;170(13):1142-1148.

50. Petrovic M, van der Cammen T, Onder G. Adverse drug reactions in older people: detection and prevention. Drugs Aging. 2012;29(6):453-462.

51. Rochon PA, Gurwitz JH. Drug therapy. Lancet. 1995;346(8966): 32-36.

52. Rochon PA, Gurwitz JH. Optimising drug treatment for elderly people: the prescribing cascade. BMJ. 1997;315(7115):1096-1099.
53. Mangoni AA. Predicting and detecting adverse drug reactions in old age: challenges and opportunities. Expert Opin Drug Metab Toxicol. 2012;8(5):527-530.

54. Brauner DJ, Muir JC, Sachs GA. Treating nondementia illnesses in patients with dementia. JAMA. 2000;283(24):3230-3235.

55. Gurwitz JH, Field TS, Harrold LR, et al. Incidence and preventability of adverse drug events among older persons in the ambulatory setting. JAMA. 2003;289(9):1107-1116.

56. Singh R, McLean-Plunckett EA, Kee R, et al. Experience with a trigger tool for identifying adverse drug events among older adults in ambulatory primary care. Qual Saf Health Care. 2009;18(3):199-204.

57. Marcum ZA, Arbogast KL, Behrens MC, et al. Utility of an adverse drug event trigger tool in Veterans Affairs nursing facilities. Consult Pharm. 2013;28(2):99-109.

58. Wu WK, Pantaleo N. Evaluation of outpatient adverse drug reactions leading to hospitalization. Am J Health Syst Pharm. 2003;60(3): $253-259$.
Clinical Interventions in Aging

\section{Publish your work in this journal}

Clinical Interventions in Aging is an international, peer-reviewed journal focusing on evidence-based reports on the value or lack thereof of treatments intended to prevent or delay the onset of maladaptive correlates of aging in human beings. This journal is indexed on PubMed Central, MedLine,

\section{Dovepress}

CAS, Scopus and the Elsevier Bibliographic databases. The manuscript management system is completely online and includes a very quick and fair peer-review system, which is all easy to use. Visit http://www.dovepress. $\mathrm{com} /$ testimonials.php to read real quotes from published authors. 